Copyright (C) 2015 by Academic Publishing House Researcher

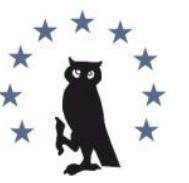

Published in the Russian Federation

European Researcher

Has been issued since 2010.

ISSN 2219-8229

E-ISSN 2224-0136

Vol. 98, Is. 9, pp. 650-657, 2015

DOI: $10.13187 /$ er.2015.99.650

www.erjournal.ru

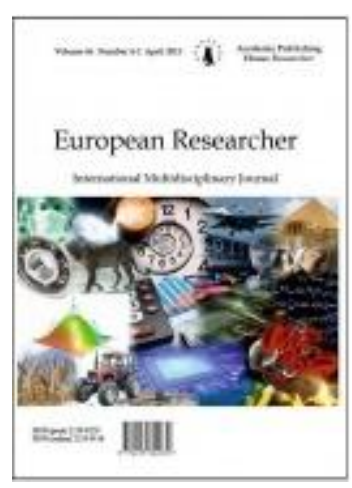

Historical sciences

Исторические науки

UDC 78

\title{
Heavy and Special Weapons across the Territory of Black Sea Coastline during the Caucasian War
}

\author{
${ }^{1}$ Aleksandr A. Cherkasov \\ ${ }^{2}$ Vladimir G. Ivantsov \\ 3 Michal Smigel \\ 4 Violetta S. Molchanova
}

${ }^{1,2}$ Sochi State University, Russian Federation

${ }^{1}$ Dr. (History), Professor

E-mail: sochioo3@rambler.ru

${ }^{2} \mathrm{PhD}$ (History), Assistant Professor

3 Matej Bel University, Slovak Republic

Doctor of Historical Sciences, Professor

4 International Network Center for Fundamental and Applied Research, Russian Federation

\begin{abstract}
The article discusses the heavy and special weapons of the Russian army during the Caucasian war across the territory of Black Sea coastline. By heavy equipment is meant all kinds of artillery systems which were used in the fortresses at that time. The particular importance is given to the special weapons, which include the minefields (mines and fougasses). It is proved that the mines on the galvanic elements were used not only in the navy but also for the needs of the ground forces. The authors came to the conclusion that the technical superiority of the Russian army became one of the main reasons for defeat of the highlanders in the war.

Keywords: heavy and special weapons, the Caucasian war, the Black Sea coastline, artillery, fougasses and mines.

\section{Введение}

В любой войне важное значение имеет технический перевес. Кто лучше вооружен, кто использует эффективные новации - за тем и остается поле боя. В условиях Кавказской войны русская администрация использовала и то, и другое для обеспечения успокоения Кавказа.

От разведчиков, эмиссаров и путешественников было известно, что черкесское Причерноморье - регион весьма не стабильный. Населяющие его племена, в значительной степени, склонны к разбою, чем серьезно осложняют жизнь соседям. Путешественникнатуралист Фредерик Дюбуа де Монперэ писал, что горцы «постоянно бьются с татарами, которые окружают их со всех сторон. Иногда они переходят Босфор по люду, чтобы грабить
\end{abstract}


татар Херсонеса Таврического; небольшая их горсть может прогнать целое полчище татар, так как они лучше вооружены, более ловки и смелы» [1].

Именно технический перевес свел к минимуму результативность горских нападений в период Кавказской войны. Горцы уже не были теми львами, которые малым числом расправлялись с крымскими татарами. Их доспехи и кольчуги не выдерживали шрапнельного огня русской артиллерии.

\section{Материалы и методы}

Материалами для написания статьи послужили специальные исследования по данной теме, а также документы Архивного отдела администрации города Сочи и государственного архива Краснодарского края.

В работе использован историко-ситуационный метод, который предполагает изучение исторических фактов в контексте изучаемой эпохи в совокупности с «соседствующими» событиями и фактами. Этот метод был применен при изучении эволюции артиллерийского и минного дела.

\section{Обсуждение}

В разное время проблемам изучения тяжелого и специального оружия периода Кавказской войны уделили внимание: В.А. Нодин, И.А. Скорик [2], Ю.Г. Веремеев [3], А.А. Черкасов [4] и др.

\section{Результаты}

\section{Тяжелые вооружения}

Тяжелые вооружения периода Кавказской войны представлены различными артиллерийскими системами.

Главным средством обороны русских крепостей служила разнообразная артиллерия. К концу XVIII в. на вооружение русской артиллерии поступили единороги, которые обладали прекрасными боевыми качествами и являлись самыми совершенными орудиями гладкоствольной артиллерии. Они были в 2-3 раза легче пушек, позволяли вести настильную и навесную стрельбу боеприпасами различных видов, сочетая в себе свойства пушек и гаубиц.

Одновременно с принятием на вооружение единорогов совершенствовались прицельные приспособления, разрабатывались подъемные механизмы орудий, улучшались свойства порохов, повышалась мощность боеприпасов. Артиллерия делилась на полевую, полковую, крепостную и осадную. Так, например, полевая артиллерия была вооружена орудиями 4 калибров (12-фунтовые пушки средней и малой пропорции, 6-фунтовые пушки и 1/4-пудовые единороги). Осадная артиллерия была вооружена 24-, 18-фунтовыми и 1-пудовыми единорогами [5].

Что же представляли собой орудия? Рассмотрим их подробнее.

I. Пушка - самое длинное из всех орудий, она не имеет каморы и предназначена для стрельбы преимущественно ядрами, а также картечью, брандскугелями и светящимися ядрами (боеприпасы мы рассмотрим далее).

Цилиндрический канал пушек оканчивается сферическим дном. В 1808 г. в полевой артиллерии произошли некоторые изменения. Так, сферическое дно было заменено плоским, соединяющимся с боковыми стенами канала небольшими закруглениями. Наружная поверхность пушек состоит из трех частей в виде усеченных конусов, которые меньшим основанием обращены к дулу.

У медных орудий диаметр запала - 2 линии, у чугунных - 21/2.

Диаметр цапф у осадных и крепостных пушек равен 1 калибру, у полевых - менее 1. Заплечики - круглые у чугунных и четырехугольные у медных пушек.

Дельфины - 2 скобы на поверхности средней части орудия, предназначенные для продевания каната при поднятии орудия. Они располагаются как можно ближе к центру тяжести орудия, а точнее, середина дельфинов лежит на касательной, проведенной к окружности цапфы со стороны казенной части. Получили свое название оттого, что раньше делались в виде различных животных, как мифических, так и реально существующих, в том числе и в виде дельфинов. 
У чугунных орудий, из-за хрупкости чугуна дельфинов не делают.

Мушка - небольшое возвышение на дульном утолщении, используемое для прицеливания. В русской артиллерии она не отливалась вместе с орудием, а делалась отдельно в виде пирамидки, ввинченной в глухое нарезное отверстие. Причем верх мушки находится на таком же расстоянии от оси орудия, что и торельный пояс, так что при прямом выстреле линия прицеливания была параллельна оси орудия.

Относительная длина пушек полевой артиллерии - от 16,5 до 17, осадной - 21, а крепостной - 20-22 калибров. Она считалась от дула до конца казенной части или до торели, т.е. не включая торель и винград.

II. Единорог - короче пушки (от 10 до 11 калибров), имеет коническую камору и служит для стрельбы в основном гранатами и бомбами, а также картечью, брандскугелями, каркасами и светящимися ядрами. Эти орудия, специфические для русской артиллерии, были разработаны М.В. Мартыновым и М.Г. Даниловым и введены в 1757 г., в бытность генерал-фельдцейхмейстера графа Шувалова, как универсальное орудие, предназначавшееся для замены как гаубиц, так и пушек. Позднее от стрельбы ядрами из единорогов отказались, и они превратились в род длинных гаубиц. Единороги получили свое название от мифического животного, изображенного на гербе Шувалова, в виде которого на ранних образцах отливались дельфины и винград.

Толщина стен в конце казенной части у медных единорогов - 1/2, в начале дульной 1/4 калибра.

Цапфы находятся в начале средней части, причем у всех единорогов, кроме 1/4пудового конной артиллерии, без заплечиков.

Дельфины, винград, мушка и запал у медных единорогов такие же, как и у пушек.

III. Мортира - самое короткое орудие, имеет цилиндрическую или коническую камору. Предназначалась для навесной стрельбы преимущественно бомбами или гранатами, а также брандскугелями, каркасами, светящимися ядрами, а иногда и картечью. В русской артиллерии применялись 5-пудовые, 2-пудовые и 6-фунтовые кугорновы мортиры.

IV. Карронада - немного короче единорогов, имеет цилиндрическую камору и служит большей частью для прицельной стрельбы ядрами, в редких случаях навесными выстрелами бомбами или гранатами. Были спроектированы в 1779 г. в Англии инженером Гаскойном для установки на кораблях, позднее применялись и для вооружения крепостей. Их отличительной особенностью был раструб в начале дула и отсутствие цапф, вместо которых использовался валик, вставляемый в проушину на нижней стороне карронады.

V. Гаубица, как и единорог, занимает промежуточное положение между пушкой и мортирой и стреляет такими же снарядами, что и единорог. В России с введением единорогов гаубицы практически перестали отливать, и они оставались в малом количестве только на вооружении крепостей. Из-за цилиндрической каморы их приходилось заряжать вручную, поэтому длина единорогов была ограничена длиной руки.

Все эти виды боевой артиллерии с успехом использовались в фортах Черноморской береговой линии. Чем же стреляли фортовые орудия?

\section{Боеприпасы}

1. Ядро - самый простой и в то же время самый распространенный снаряд. Представляет собой сплошной чугунный шар, наносящий вред ударом. Ядрами преимущественно стреляли из пушек, а также из 3-фунтовых единорогов при малых углах возвышения и большими зарядами.

Размеры русских снарядов были установлены еще при Петре I. Генералфельдцейхмейстер граф Брюс ввел артиллерийскую шкалу, единицей измерения которой были приняты английские дюймы. За основу было взято чугунное ядро диаметром в 2", получившее название фунтового. Этот условный вес, названный артиллерийским, применялся только для определения диаметров ядер. Для взвешивания других предметов в русской артиллерии применялся обыкновенный торговый вес. Поэтому численное выражение артиллерийского фунта большого значения не имело, и многие артиллеристы путали его с нюрнбергским фунтом. Маркевич на основании своих опытов по определению плотности чугуна выяснил, что артиллерийский фунт почти в 1,19 раза больше, чем торговый. 
При приготовлении готового заряда с ядром сначала его присмаливали к деревянному поддону, называемому шпигелем. Одна его сторона, обращенная к пороху, - плоская, а другая имеет сферическое углубление в $1 / 3$ диаметра ядра, куда оно и вставляется. Около плоского дна шпигеля протачивается желоб для привязывания к картузу. Ядро со шпигелем вставляют в картуз, положив предварительно на порох паклю, чтобы он не проникал между картузом и сторонами шпигеля. Затем стеклядью (тонкой веревкой) картуз обвязывается вокруг желоба на шпигеле и связывается над ядром.

2. Граната - чугунный шар весом менее пуда, имеющий внутри пустоту, в которую насыпан порох (разрывной заряд). Подобный снаряд, но весом в пуд и более называется бомбой. В сквозное отверстие, сделанное в стене гранаты, называемое очком, вставляется гранатная трубка (современное название - дистанционная трубка) - деревянный усеченный конус с отверстием, набитым горючим составом. Чтобы трубка лучше держалась, наружный диаметр очка делается несколько больше внутреннего. При воспламенении заряда в орудии состав в трубке загорается. Когда весь состав в трубке сгорает, огонь сообщается разрывному заряду, от действия которого снаряд разрывается на куски - черепья или осколки. Поэтому, в отличие от ядра, эти снаряды обладали и осколочно-фугасным действием, т.е. поражали не только ударом, но и осколками и взрывной волной.

Граната или бомба с разрывным зарядом называется заряженной, а полностью готовая, с трубкой - снаряженной. Для того чтобы снаряд не падал трубкой вперед и не затухал, противоположную от очка часть делали более тяжелой.

Для определения диаметров русских гранат и бомб был взят диаметр 10-фунтового ядра (по артиллерийскому весу). Граната такого диаметра была названа 8-фунтовой, причем ее вес почти равнялся 8 торговым фунтам. Как видим, в России был еще один условный вес, но из-за близости к торговому его особо не выделяли. Отсюда легко находится диаметр фунтовой гранаты, который равен половине диаметра 10-фунтового ядра. Зазор для гранат и бомб был больше зазора для ядер - калибры орудий относились к диаметрам гранат и бомб как 48:46. Так как из-за пропорциональности диаметру снаряда зазоры у крупнокалиберных орудий получались слишком большими, в 1808 г. для них были приняты одинаковые зазоры в 1,75 линии, при этом калибры остались старыми, а увеличились диаметры снарядов. Это касается и пушек калибром от 18 фунтов и выше.

3. Kaртечь применялась исключительно для поражения живой силы противника. Особенно эффективна она была, если войска противника располагались развернутым фронтом или широкой колонной. На вооружении русской армии находилась картечь двух видов - вязаная и жестяная; последняя подразделялась на дальнюю и ближнюю.

Жестяная картечь - снаряд, состоящий из чугунных пуль, уложенных в определенном порядке в жестяном цилиндре. Нижним основанием цилиндра служит железный поддон, верхний же ряд пуль покрыт кружком из листового железа, на который загнуты зубчатые края цилиндра. Картечь помещается в орудие поддоном к заряду. При выстреле поддон передает пулям давление пороховых газов, отчего одни пули втискиваются в промежутки между другими, передавая давление во все стороны, разрывают цилиндр и вылетают из орудия, разлетаясь в стороны от оси канала.

Дальняя картечь состояла из малого числа пуль большого калибра и, как видно из названия, применялась для стрельбы на большие расстояния. Ближняя, соответственно, имела больше пуль, но меньшего калибра. Вообще вес целой картечи (пуль, жестяного цилиндра и поддона) для всех орудий был в 1,5-2 раза больше веса того снаряда, от которого орудие получает свое название. Несмотря на это, скорострельность картечью была выше, чем ядрами за счет менее тщательного прицеливания.

4. Брандскугель (зажигательное ядро, брандскугель, от нем. brand - огонь и kugel ядро) - чугунный шар со сферической пустотой, имеющий 3-5 (в полевой артиллерии - 3) отверстий и наполненный зажигательным составом. Служил для поджигания различных предметов. При выстреле огонь передавался через отверстия составу внутри ядра, и из них начинало вырываться пламя, от которого загоралось вокруг все, что может гореть. Наносило вред также ударом.

Как и гранаты, брандскугели осмаливали, затем забивали отверстия деревянными гвоздями, кроме одного, через которое просовывали брандскугельный состав, состоящий из: 
пороха - 12 частей; мякоти - 12; смолы - 71/2; селитры - 21/2; сала свечного - 1; воска - 1/2; канифоли - 1/2; льна или тряпиц, мелко изрубленных $-1 / 16$.

После остывания заряда гвозди вынимали. Отверстия приготавливали таким же способом, как и гранатные трубки, но с использованием свечного состава, т.е. вставляли крест-накрест куски стопина, прибиваются составом, пока не останется $1 / 4$ ", куда кругом укладывали концы стопина и присыпали мякотью. Затем отверстие прикрывали лоскутом писчей бумаги, на который накладывали пропитанный смолой четырехугольный пластырь из холста. К шпигелю брандскугели присмаливались так, чтобы все отверстия отстояли от краев на равном расстоянии и были вне чашки шпигеля. Картуз, как у гранат, обшивался так, чтобы отверстия остались незакрытыми.

Каждое орудие было снабжено банником, прибойником ${ }^{\dagger}$, а также имелись: фитильный пальник, фитильный ночник , свечник, или свечной футляр, зарядная сума, трубочная лядунка, или трубочник, протравник, пыжевник, трещотка, прицел и другие предметы.

В 1803 г. вместо зарядных фургонов введены двухколесные зарядные ящики. С этого времени каждое орудие имело 2-3 снарядных ящика с 40-90 снарядами в каждом. В 1811 г. артиллерийский прицел системы Маркевича был заменен прицелом Кабанова. В 1845 г., в период Кавказской войны, были приняты на вооружение новые, более легкие артиллерийские лафеты. В целом гладкоствольная артиллерия к середине XIX в. достигла вершины своего развития.

\section{Специальное оружие. Минное оружие.}

Черноморская береговая линия, как известно, представляла собой цепь крепостных сооружений. В центре линии, находились укрепления Навагинское и Головинское. Именно вокруг этих укреплений с момента своего существования фиксировалась повышенная горская активность, в том числе с применением артиллерии [6]. Оба укрепления находились на территории одного из самых воинствующих племен горцев Черноморья - убыхов.

Как вариант было предложено защищать крепость при помощи минных полей и фугасов.

К этому времени русское военное дело уже дошло до более надежного электрического способа подрыва мин и фугасов. Как известно в 1822 году этот способ был изобретен русским военным инженером П.Л. Шиллингом, а применен спустя 12 лет начальником инженеров Гвардейского корпуса генерал-майором К.А. Шильдером. Нужно отметить, что европейцы даже в Крымскую кампанию (1854-1956 гг.) приводили мины в действие при помощи менее надежного огневого способа. Исторически сложилось полагать, что мины на электрическом способе подрыва использовались только во флоте [7], на самом же деле мы хотим продемонстрировать конкретный случай долговременного использования мин для защиты одной из крепостей Черноморской береговой линии.

В апреле 1847 г. в штабе Черноморской береговой линии начал обсуждаться вопрос об установке мин вокруг русских укреплений. Для обучения минному делу в Керчь были командированы чины лейб-гвардии саперного батальона Черноморской береговой линии, куда они были направлены в обстановке повышенной секретности [8]. Закладка мин производилась только в двух укреплениях Черноморской береговой линии (форты Навагинский и Головинский) и в Чечне.

\footnotetext{
* Щетинная щетка, насаженная на древко, имеющая форму и размеры задней части канала или каморы того орудия, к которому принадлежит, т.е. цилиндр для пушек и усеченный конус для единорогов.

${ }^{\dagger}$ Деревянный цилиндр (стакан) или усеченный конус, насаженный на древко. Применялся для досылания заряда до дна канала или каморы.

₹ Деревянное древко, имеющее на одном конце железные щипцы с винтом, в которые вставлялся тлеющий конец фитиля, остальная часть которого обматывалась вокруг древка.

$\S$ Служил для сохранения зажженного фитиля в дождливое время.
} 
С 1848 г. начинается закладка мин и фугасов вокруг форта Навагинского [9]. Так, 25 и 26 мая были установлены в две линии 13 мин на расстоянии друг от друга в 5-6 сажень*. Кроме того, 2 фугаса по 1,5 пуда пороху были установлены на горе Батарейка, управление которыми осуществлялось по проводам из укрепления. На рис. 1. видна траншея, которая ведет от крепости к горе. Подступы к юго-восточному бастиону были заминированы 3 камнеметными проводными фугасами. 25 мая 1848 г. они были впервые введены в действие. Произошло это следующим образом: во время отступления отряда, установившего мины, на горе Батарейке, как раз на месте фугасов, показались горцы. Первый фугас был приведен в действие и разметал горцев. Ничего не понявшие горцы вечером опять появились на горе - в действие был приведен второй фугас. В июле того же года после сильных дождей с разрешения командующего Черноморской береговой линией в целях проверки был удачно приведен в действие третий фугас [10]. Необходимо отметить, что после приведения в действие фугаса на его месте спешно, при первой возможности, устанавливался новый фугас. Таким образом, линия обеспечения перед фортом не страдала и находилась в постоянной боевой готовности.

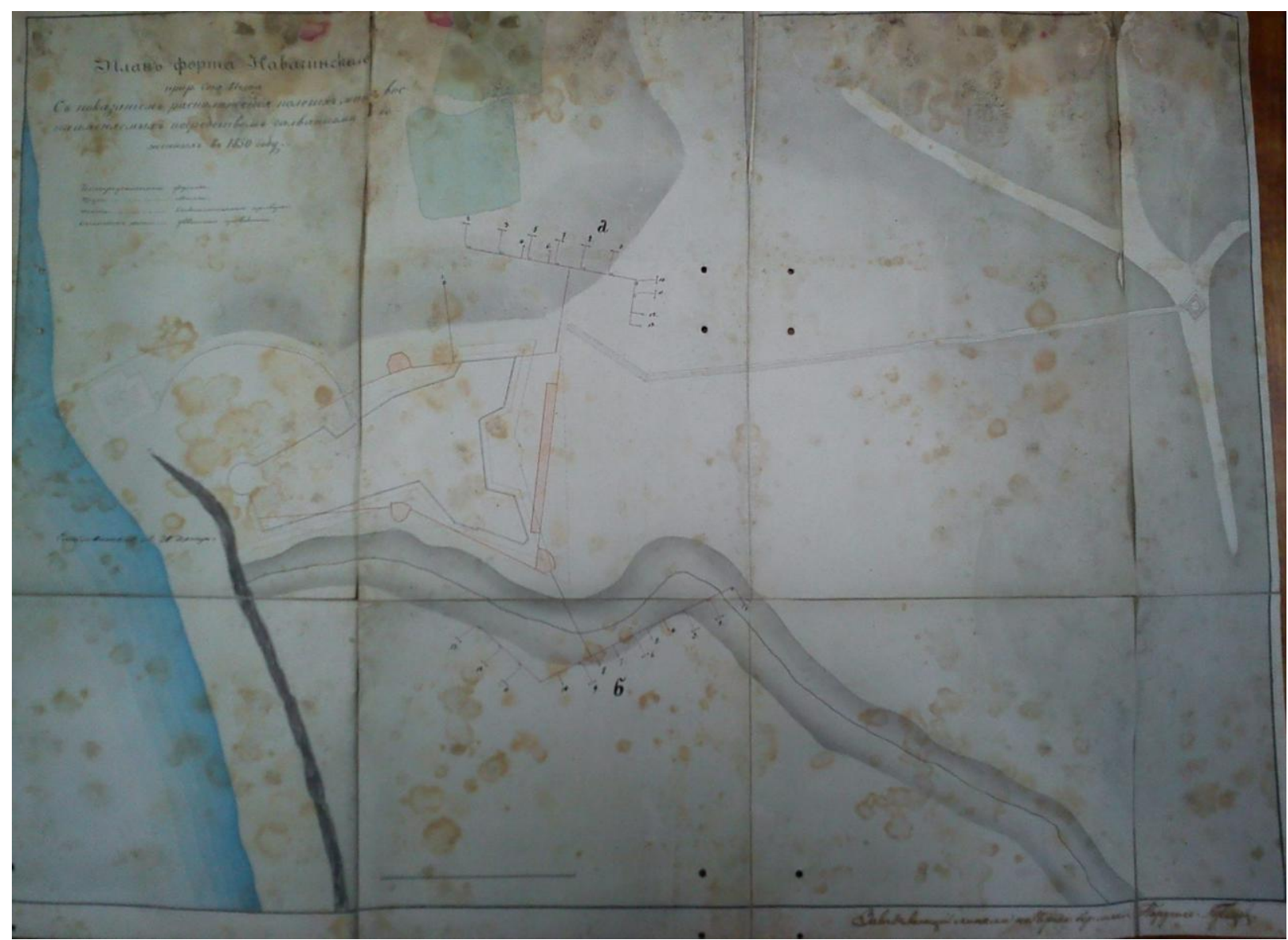

Puc. 1. План форта Навагинского и схема расположения минных полей и фугасов. Публикуется впервые

В ночь с 9 на 10 апреля 1849 г. в форте произошел крупный пожар, в ходе которого сгорели все солдатские казармы [11]. Горцы наблюдали зарево пожара в форте Навагинском, однако наличие фугасов заставило их не предпринимать нападения в целях окончательного разгрома форта [12]. Именно перспектива бесславной кончины на минном поле удерживала горскую вольницу от штурма.

\footnotetext{
${ }^{*}$ Сажень - 2,1 метра.
} 
Позднее закладка мин осуществлялась и в июне 1850 г., занимался их установкой поручик Кавказского саперного батальона Кузнецов. В это время было заложено 28 мин на подступах к форту, а также 3 мины на горе Батарейка [13].

Фугасы были по 1,5 пуда пороху, а мины - по 20 фунтов [14]. Фугасы хранились в металлических непроницаемых для влаги ящиках.

Необходимо отметить, что горцы препятствовали работам в так называемой нейтральной зоне. Так, во время минирования, которое осуществлялось 20 июня, произошли перестрелки с горцами. В ходе этих столкновений гарнизон потерял убитыми 6 человек (2 унтер-офицера и 4 рядовых), а также 1 рядовой был ранен [15]. На протяжении всего 1850 г. время от времени, при обнаружении горцев, мины приводились в действие. Так, были подорваны три камнеметных фугаса: 20 июня на горе Батарейка, 19 августа перед северо-восточным бастионом и 15 сентября на левом фланге юго-восточных мин [16].

Минные заграждения несли свою службу в течение длительного периода - с 1848 г. по весну 1851 г. За это время, по свидетельству иеромонаха Ксенофонта (гарнизонный священник Авт.), вокруг крепости прекратились даже «мелкие шалости и воровство горцев» [17]. Однако в 1851 году было обнаружено, что две мины похищены горцами. Дело о краже мин находилось на контроле у императора Николая I. В ходе следствия было выяснено, что секрет мин раскрыл бежавший к горцам дезертир. В результате этого оставшиеся мины пришлось в спешном порядке снять.

Тем не менее, опыт применения минных заграждений на суше, в охране крепости был успешным, так как смог сохранить жизни многих солдат и офицеров Кавказской армии.

\section{Заключение}

Завершая хочется отметить, что техническое превосходство Русской армии стало одной из основных причин поражения горцев в войне. За десятилетия ведения боевых действий были апробированы новые виды боеприпасов для артиллерии, тактические приемы, минные заграждения, а самое главное был накоплен боевой опыт. Именно поэтому русская армия периода Николая І отличалась своей повышенной боеспособностью.

\section{Благодарности}

Статья подготовлена в рамках фундаментальной темы НИР «Кавказ в диалоге цивилизаций: механизмы глобальных изменений (опыт XVIII-XIX вв.)». Сочи, 2014-2015.

\section{Примечания:}

1. Фредерик Дюбуа де Монперэ. Путешествие вокруг Кавказа. Т. 1. У черкесов и абхазов. Майкоп, 2010. С. 24.

2. Нодин В.А., Скорик И.А. и др. Артиллерия. М., 1972. С. 22-23.

3. Веремеев Ю.Г. Мины вчера, сегодня, завтра: http://coollib.com/b/268185/read\#2 (Режим открытого доступа. Дата обращения. 1.09.2015 г.)

4. Cherkasov, A.A., Ryabtsev, A.A., Menkovsky, V.I., Tarakanov, V.V., Navrotsky, A.V. By royal authority (Investigation data, concerning mines theft in fort navaginsky of the black sea coastal frontier. 1851) // Былые годы. 2013. № 1 (27): 5-15.

5. Нодин В.А., Скорик И.А. и др. Артиллерия. М., 1972. С. 22-23.

6. Архивный отдел администрации города Сочи (АОАГС). Ф. Р-348. Оп. 1. Д. 8. Л. 19-20.

7. Веремеев Ю.Г. Мины вчера, сегодня, завтра: http://coollib.com/b/268185/read\#2 (Режим открытого доступа. Дата обращения. 1.09.2015 г.)

8. Государственный архив Краснодарского края (ГАКК). Ф. 26о. Оп. 1. Д. 1189. Л. 199.

9. ГАКК. Ф. 260. ОП. 1. Д. 1189. Л. 299.

10. ГАКК. Ф. 260. ОП. 1. Д. 1189. Л. 50.

11. ГАКК. Ф. 260. ОП. 1. Д. 817. Л. 9.

12. АОАГС. Ф. Р-348. ОП. 1. Д. 10. Л. 59.

13. ГАКК. Ф. 260. Оп. 1. Д. 1189. Л. 500б.

14. ГАКК. Ф. 260. ОП. 1. Д. 1189. Л. 57.

15. ГАКК. Ф. 260. Оп. 1. Д. 1169. Л. 298.

16. ГАКК. Ф. 260. ОП. 1. Д. 1189. Л. 50. 
17. ГАКК. Ф. 260. ОП. 1. Д. 1189. Л. 299.

References:

1. Frederik Dyubua de Monpere. Puteshestvie vokrug Kavkaza. T. 1. U cherkesov i abkhazov. Maikop, 2010. S. 24.

2. Nodin V.A., Skorik I.A. i dr. Artilleriya. M., 1972. S. 22-23.

3. Veremeev Yu.G. Miny vchera, segodnya, zavtra: http://coollib.com/b/268185/read\#2 (Rezhim otkrytogo dostupa. Data obrashcheniya. 1.09.2015 g.)

4. Cherkasov, A.A., Ryabtsev, A.A., Menkovsky, V.I., Tarakanov, V.V., Navrotsky, A.V. (2013) By royal authority (Investigation data, concerning mines theft in fort navaginsky of the black sea coastal frontier. 1851) Bylye Gody. (1), 27: 5-15.

5. Nodin V.A., Skorik I.A. i dr. Artilleriya. M., 1972. S. 22-23.

6. Arkhivnyi otdel administratsii goroda Sochi (AOAGS). F. R-348. Op. 1. D. 8. L. 19-20.

7. Veremeev Yu.G. Miny vchera, segodnya, zavtra: http://coollib.com/b/268185/read\#2 (Rezhim otkrytogo dostupa. Data obrashcheniya. 1.09.2015 g.)

8. Gosudarstvennyi arkhiv Krasnodarskogo kraya (GAKK). F. 260. Op. 1. D. 1189. L. 199.

9. GAKK. F. 260. Op. 1. D. 1189. L. 299.

10. GAKK. F. 260. Op. 1. D. 1189. L. 50.

11. GAKK. F. 260. Op. 1. D. 817. L. 9.

12. AOAGS. F. R-348. Op. 1. D. 10. L. 59.

13. GAKK. F. 260. Op. 1. D. 1189. L. 50ob.

14. GAKK. F. 260. Op. 1. D. 1189. L. 57.

15. GAKK. F. 260. Op. 1. D. 1169. L. 298.

16. GAKK. F. 260. Op. 1. D. 1189. L. 50.

17. GAKK. F. 260. Op. 1. D. 1189. L. 299.

УДК 78

\title{
Тяжелые и специальные вооружения на территории Черноморской береговой линии в период Кавказской войны
}

\author{
${ }^{1}$ Александр Арвелодович Черкасов \\ ${ }^{2}$ Владимир Гаврилович Иванцов \\ з Михал Шмигель \\ ${ }_{4}^{4}$ Виолетта Сергеевна Молчанова
}

\begin{abstract}
1,2 Сочинский государственный университет, Российская Федерация
1 Доктор исторических наук, ведущий научный сотрудник

E-mail: sochioo3@rambler.ru

${ }^{2}$ кандидат исторических наук, старший научный сотрудник

3 Университет Матея Бела, Словакия

Доктор истории

4 Международный сетевой центр фундаментальных и прикладных исследований, Российская Федерация
\end{abstract}

Аннотация. В статье рассматриваются тяжелые и специальные вооружения Русской армии в период Кавказской войны на территории Черноморской береговой линии. Под тяжелыми вооружениями понимаются все виды артиллерийских систем, которые использовались в крепостях в это время. Особое значение придается специальным вооружениям, к которым отнесены минные заграждения (мины и фугасы). В статье доказывается, что мины на гальванических элементах использовались не только во флоте, но и для нужд сухопутной армии. В заключении авторы приходят к выводу, что именно техническое превосходство Русской армии стало одной из основных причин поражения горцев в войне.

Ключевые слова: тяжелые и специальные вооружения, Кавказская война, Черноморская береговая линия, артиллерия, фугасы и мины. 